\title{
Knowledge and Truth in Virtuous Deliberation
}

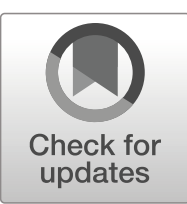

\section{David Carr ${ }^{1}$}

Received: 20 June 2019 / Accepted: 24 January 2020 /

Published online: 3 February 2020

(C) The Author(s) 2020

\begin{abstract}
The overall aim of this paper is to explore the role of knowledge and truth in the practical deliberation of candidate virtuous agents. To this end, the paper considers three criticisms of Julia Driver's recent defence of the prospect of 'virtues of ignorance' or virtues for which knowledge may be considered unnecessary or untoward. While the present essay agrees with the general drift of Driver's critics that we should reject such virtues construed as traits that deliberately embrace ignorance, it is more sympathetic to the suggestion that virtue and virtues may need to accommodate some absence or deficit of knowledge and proceeds to further scrutiny of this possibility. More radically, however, the paper concludes by arguing that while knowledge is an overall desideratum of virtue and virtuous conduct, there are circumstances in which even complete knowledge may be insufficient to identify or determine the precise course and direction of such conduct.
\end{abstract}

Keywords Knowledge $\cdot$ Truth $\cdot$ Virtue $\cdot$ Moral character $\cdot$ Practical deliberation

'Don't you know that a true falsehood (if you'll allow me the phrase) is loathed by everyone, divine or human? ...no one chooses and wants to be denied in the most important part of himself and about the most important things. The presence of falsehood there is his worst fear.' (Socrates in Plato 1993, 382a, p. 77).

\section{Virtue and Truth}

In the above quotation from the Republic, Socrates places a value on truth and truth-telling that is clearly - here and elsewhere in Plato's Socratic dialogues - quite central to his conception of virtue. Indeed, the idea that the main obstacle to the cultivation of virtue lies

David Carr

David.Carr@ed.ac.uk

1 Moray House School of Education, University of Edinburgh, Holyrood Road, Edinburgh EH8

$8 \mathrm{AQ}, \mathrm{UK}$ 
in a common human susceptibility to ignorance and/or deception - by the senses, self or others - is evidently the dominant theme of Plato's ethics. In short, for Socrates and Plato, the chief route to virtue is accurate perception of the world, ourselves and our relations with others and the moral wisdom of virtue requires knowledge of objective truth that frees us fom the bonds of ignorance and deception. For both Socrates and Plato, key obstacles to such accurate moral and other perception are sensible experience and affective responses to such experience that might only be remedied or corrected by the right - rational or logical - use of reason: right reason delivers knowledge, whereas the senses and feeling cannot. So while both Socrates and Plato espouse a form of 'virtue ethics', it is one in which the pursuit of knowledge by reason dominates and takes precedence over other less rational aspects of human nature. Socrates, in particular, appears to have defended a strong 'internalist' conception of the relation between knowledge and virtue, whereby the former is both necessary and sufficient for the latter: at any rate, it renders virtue in the absence of knowledge largely inconceivable.

Still, while more might be said on behalf of the Socratic account than much modern criticism has allowed (Carr 2016), it is no less easy to see why any tight connection between knowledge and virtue has been resisted. The most familiar objection is that knowledge cannot be considered sufficient for virtue, since we commonly hold agents accountable for bad behaviour despite their clear knowledge that it is bad. To any possible Socratic response that such agents cannot therefore really have known what they were doing, it can yet be replied that fully knowledgeable agents may be incapacitated from appropriate agency in ways beyond their reasonable control - and, indeed, Plato himself evidently doubted that knowledge is sufficient for virtue without some affective or other motivational support. However, it may be a greater difficulty for the connection between knowledge and virtue that the former is not even necessary for the latter. While this has ever been a threat from pre-Socratic no less than post-Platonic (especially modern sentimentalist) ethics, it has taken an interesting new turn with recent revival of the virtue ethics of Plato's great pupil Aristotle. As well known, Aristotle's ethics departs most significantly from Plato's in its practical turn: namely, in its rejection of Plato's more 'intellectual' conception of moral knowledge - or, at least, of the role that such knowledge is alleged by Plato to play in virtue - and in its better accommodation of the non-rational aspects of human nature to moral life and conduct (Aristotle 1941). While contemporary forms of virtue ethics have greatly diversified under the influence of other philosophers besides Aristotle - so that it is no longer helpful to think of modern virtue ethics as one unified perspective (see Carr et al. 2017) - most have nevertheless followed this practical Aristotelian turn and inclined to locate virtue in relatively stable traits of human character (of, for example, courage, self-control and fair dealing) arguably conducive to beneficial or 'flourishing' personal or social agency.

Still, it would seem that the 'eudaimonistic' drift of such emphasis on the personal and social consequences of moral agency - much reinforced by explicit Aristotelian separation of theoretical enquiry from practical deliberation (Aristotle 1941, book 6) and his occasional comparison of virtue cultivation to skill acquisition (Aristotle 1941, book 2, 1103b, 953 ) - has also encouraged more instrumental accounts of virtue in which Socratic and Platonic concern with its epistemic dimensions is not greatly to the fore. An extreme (though by no means unique) instance of this may be seen in Julia Driver's recent defence of the notion of 'virtues of ignorance' (Driver 1989, 2001) in which knowledge not only takes a moral back-seat, but is also considered potentially impedimental to the exercise of 
at least some virtues. While it is the main aim of this paper to clarify the overall role of knowledge in virtue - or of the stronger and weaker senses of knowledge that may be unhelpfully confused in latter-day discussions of this issue - the next section will first give space to recent criticism of Driver's virtues of ignorance as a helpful step towards attending to such wider epistemic concerns. However, while the present essay is generally sympathetic to the prevailing critical drift that virtues of ignorance are ethically unacceptable, it also agrees that some of this criticism opens up interesting possibilities for virtues in the absence of knowledge. Indeed, closer attention to the logic of Aristotelian practical reason in the third section of this paper will serve to show that Aristotle's plausible distinction of moral deliberation from epistemic enquiry permits much room for shortfall between virtue and knowledge, precisely allowing - as argued more fully in the fourth section - for cases of genuine virtue in spite of, albeit not because of, lesser or greater ignorance. Still, the fifth section of this paper explores a moral case for the epistemically well-grounded exercise of some virtues - such as love, trust and forgiveness - in circumstances in which these are at some odds with the justice that other virtues might appear to require: in short, it is argued that there can be significant tension or conflict between the agentic requirements of virtue even given substantial moral-epistemic agreement. First, however, to Driver's virtues of ignorance.

\section{Virtues of Ignorance}

As already noted, while modern virtue ethics has clear Aristotelian origins, it is now a garden of diverse blooms in which Aristotle is by no means always the dominant philosophical influence and virtue or virtues are sometimes linked to or derived from ethical theories such as deontology or utilitarianism - formerly considered at some variance with any primary focus on virtuous character. In this light, Julia Driver $(1989,2001)$ has lately defended a consequentialist version of virtue ethics in which emphasis is placed largely on the (eudaimonic) ends of moral agency to which virtues of character are largely conceived as useful means. So considered, any knowledge upon which virtues may draw need play no vital role in their effective exercise - especially if, as it were, it 'gets in the way' of successful achievement of the practical ends to which such virtues are otherwise devoted. Thus, Driver has argued for a class of 'virtues of ignorance' in which some knowledge deficit is an actual requirement of genuinely possessing virtue of this kind. Her showcase example of such virtue is modesty, which - so she claims - no-one could openly profess (since to declare oneself modest would seem self-contradictorily immodest) and in which accurate estimate of one's talents or accomplishments seems also precluded by requirement of the modest to underestimate their achievements. This seems to be about as far as one can get from the old Socratic connection of virtue with knowledge. However, three recent critical responses to Driver's virtues of ignorance will now be considered.

In his paper 'Virtue and ignorance', Owen Flanagan (1990) resists Driver's ignorant virtues on several counts. Generally, he rejects the claim that virtues of ignorance do not require knowledge and truth on the grounds that her account equivocates between stronger and weaker senses of knowledge. Significantly for the present discussion, he argues that few philosophers would (presumably especially nowadays) take moral virtue to entail knowledge in the strong theoretical or propositional sense that Driver takes to be denied by her virtues of ignorance. However, with particular regard to her favoured example of 
modesty, he also maintains: first, that genuine modesty is inconsistent neither with knowledge that one is modest nor with accurate assessment of one's achievements; second, that deliberate underestimation of such achievements or worth could hardly count as modesty or any other virtue. Briefly, in place of Driver's 'underestimation' conception of modesty, Flanagan proposes a 'non-overestimation' account: on this view, while deliberate underestimation of one's worth or achievements can hardly be counted virtuous, over-estimation of them is no less morally objectionable. Thus, modesty aims at an appropriate 'Aristotelian' mean between such unacceptable extremes. Generally, Flanagan's response points towards large and complex questions about the status and role of reason and knowledge in virtuous deliberation to which we shall need to return after considering other responses to Driver at some odds with his.

In his paper 'Ignorance and virtue', Ronald Sandler (2005) also rejects Driver's argument that some virtues actually require ignorance in favour of a view that there are - or at least may be - virtues that could or may need to accommodate it. Although Sandler does include modesty among such potential ignorance-compatible virtues, his own favoured example of such a disposition is tolerance. While also leaving it open whether there is such a virtue, he suggests the following definition:

'The virtue of tolerance is the disposition to respond excellently in instances when one maintains a negative evaluation of some object and believes one possesses some capacity to eliminate or interfere with that object.' (Sandler 2005, 265).

Sandler defends such tolerance against possible objections to its morally 'paradoxical' nature - namely, that we could or should not (consistently) deplore some action or perspective without taking steps to prevent or oppose it - on essentially 'liberal' grounds of human epistemic limitation. Insofar as such limitation precludes our certain knowledge that what we believe (at least about some matters) is correct, and that the opposing beliefs of others are therefore mistaken, a degree of tolerance of views we dislike - assuming, presumably, that such views are not actually harmful to others seems reasonable in the interests of (inter alia) social harmony and cohesion.

However, Sandler also holds that modesty is or may be appropriate on much the same grounds of epistemic limitation: the fact that we cannot, from a larger human perspective, be sure of the precise significance or value of our own worth or achievements - especially vis-a-vis those of our fellows - speaks in favour of a reasonable degree of agnosticism in this direction. All the same, like Flanagan, Sandler roundly rejects Driver's view of modesty as a disposition to ignorance: on his view, ignorance is neither a goal of nor necessary to modesty which is entirely consistent with accurate assessment of our worth or achievements, and/or with reasonable judgement of ourselves as modest. That said, Sandler distinguishes his own view of such ignoranceaccommodating virtues as tolerance and modesty from what he regards as 'cognitive' conceptions of such virtues, in which he includes the accounts of both Driver and Flanagan. His point is that such virtues should be construed neither in terms of knowledge nor of ignorance: on the contrary, they are reasonable responses to appropriate agnosticism about what we can or cannot know in view of human epistemic limits. This is especially true of tolerance which is clearly based less on substantial knowledge of anything, more on the impossibility of our knowing everything. In the present view, Sandler's case for tolerance as a virtue of ignorance is more compelling 
than his account of modesty. Still, be that as it may, we may now turn to a rather more recent response to Driver.

Michael Winter's paper 'Does moral virtue require knowledge? A response to Julia Driver' (Winter 2012) does not acknowledge the critiques of either Flanagan or Sandler, but it differs from their accounts at some significant points. At all events, taking Driver to be offering a generally sceptical challenge to the traditional view that virtue and virtues require knowledge, the first half of his paper aims to show that her virtues of ignorance do not successfully deliver on this challenge. Again focusing, like Flanagan and Sandler, on Driver's account of modesty as her strongest case against any general knowledge requirement for virtue, Winter seeks to show - on the basis of a range of examples - that there can be no genuine modesty in the face of wilful ignorance. In his view, if Driver's main case is that there can be virtues without knowledge and her best instance is modesty, then she has not succeeded in pressing this claim. Like Flanagan and Sandler, Winter offers a definition or account of modesty which, however, appears to differ somewhat from theirs. According to his account, modesty needs to meet three conditions: (i) that modest agents have accomplishments; (ii) that they are aware of such accomplishments; (iii) that they nevertheless refrain from 'putting these forward'. On the face of it, this differs from Sandler's account insofar as it is (like Flanagan's) 'cognitivist', and from Flanagan's nonoverestimation view in that (iii) would not appear to lie in any obvious Aristotelian mean.

In the second half of his paper, Winter turns to Driver's doubts about the need for moral intention in virtuous deliberation. In standard accounts of the practical wisdom of virtue, virtue requires that agents form an intention - understood as a clear reason for action based on some general principle of effective virtuous or moral agency. However, in those cases where agents act upon an irrational desire or some other affective motive contrary to moral principle, they are usually taken to to have acted from akrasia or weakness of will. Against this, Driver draws on a much discussed and anomalous example from Mark Twain's novel Huckleberry Finn in which the eponymous hero seems to act on the basis of non-rational affect (fellow feeling for the escaped slave Jim) against his culturally conditioned belief (that escaped slaves should be turned in), but - in so doing - evidently acts more virtuously than otherwise. While Winter agrees with Driver that it seems untoward to regard Huck's action of helping Jim as mere akrasia (moral failure through personal weakness), and better to regard it as virtuous, he resists her essentially sentimentalist account of this as a matter of non-rational feeling more than principled (knowledge informed) intention. He argues instead for an alternative construal of Huck's seemingly affective response as implicitly mindful of a morally superior principle (of helping others in human need) to that into which he had been hitherto conditioned. Hence, if we also plausibly take it that not all genuine moral intentions have to be consciously registered or entertained, Huck's sympathy for Jim can and/or should be interpreted as symptomatic of principled moral virtue rather than mere affect-driven weakness.

While the points of Driver's critics all have their merits, they are significantly different, not obviously consistent - at least in their accounts of the virtue of modesty - and their respective bearing on the general epistemic status of virtue is far from entirely clear. The clearest point of agreement would seem to be common rejection of Driver's virtues of ignorance - as explicitly concerned to foster or promote knowledge deficit - as normatively objectionable or incoherent. That said, Sandler's contention that some virtues - such as tolerance - may be needed in the absence of knowledge opens up a case for shortfall between knowledge and virtue upon which we shall 
shortly elaborate further. Still, the larger positions of Driver's critics on the respects in which knowledge is implicated in virtuous deliberation seem less clear. As already noted, Flanagan distinguishes between 'strong' and 'weak' senses of virtuous knowledge, suggesting that virtue ethicists have not generally required knowledge in the stronger sense for virtue or virtues. Insofar as Flanagan actually refers to such strong knowledge as 'propositional' or 'declarative' he may be implying - with some justification - that many if not most recent virtue ethicists have taken the knowledge of virtuous deliberation to be more like the practical or procedural knowledge of 'knowing how' than the theoretical or propositional knowledge of 'knowing that'.

All the same, regardless of any or all other virtue ethical views on this matter, it would seem that Flanagan himself endorses what Sandler calls a 'cognitivist' view of virtuous modesty as essentially consistent with (if not requring) epistemically accurate assessment of one's own worth and/or achievements. In short, if such cognitivism means factually accurate assessment of one's own personal status regarding the possession or otherwise of some virtue and/or of the more specific conditions of heart and mind whereupon such assessment might be accurately based - as Flanagan's critique of Driver seems to allow - it would seem to involve significant strong knowledge in his sense. Likewise, some such commitment to the role of strong ('propositional') knowledge in virtuous reflection or deliberation would also seem to be a feature of Winter's critique of Driver. So far as one can tell, Winter would seem to take such strong knowledge to be implicated at the very least in the minor premise of practical syllogisms - precisely in the knowledge of what needs to be done in particular circumstances to substantiate any virtuous intention - but it may also be that he takes this, along with the grasp the more general principle of major premise, to comprise some larger knowledge of strong sense. If so, then this seems a more problematic position to which we shall now need to pay closer attention via further consideration of the epistemic status and structure of the Aristotelian practical deliberation of phronesis.

\section{Knowledge in Practical Deliberation and Virtue}

As earlier indicated, Aristotle's main ethical departure from Plato lies in his effective rejection the former's 'intellectual' approach to moral enquiry in favour of a more practical account of virtuous deliberation and conduct: for Aristotle, the aim of moral deliberation is not theoretical knowledge of the good but good or virtuous conduct. Indeed, insofar as there may be no uncertainty in the realm of genuine theoretical knowledge - which is either true or false - this does not call for the more approximate deliberation and judgement needed for the greater uncertainties of human practical affairs. Moreover, this practical Aristotelian turn seems quite radical, not least with regard to Aristotle's explicit comparison - enormously influential on recent neo-Aristotelian virtue ethics (see, Annas 2011; Stichter 2018) - of the cultivation of virtues with the acquisition of other practical tasks and abilities: agents become virtuous, according to Aristotle, by the practise of temperate, courageous and other virtuous acts in much the same way that they become skilled musicians or builders by performances of music or construction. Indeed, while in book 6 Aristotle clearly distinguishes two kinds of intellectual virtue - or forms of reasoning - as 'practical', his Nicomachean Ethics observes little or no formal difference between the means-end inference of techne or technical reasoning on the one hand and 
moral wisdom or phronesis on the other. In the standard Aristotelian account, such inference takes the form of: (i) a general major premise (eg. all humans need nourishment) - also apt for hypothetical formulation (ie. if one is human, then one needs nourishment); (ii) a minor premise affirming the antecedent of the hypothetical (I am human); and (iii) an imperative conclusion (ie. I should take nourishment). But it may be possible to analyse almost any rational practical activity - for example, taking exercise for health, composing a symphony, building a shed or trying to treat others fairly - in terms of complex strings of such means-end reasoning. From this perspective, however, practical inference seems to typify more a kind of 'know-how' than a form of theoretical knowledge or knowing that even if, as we shall see, the latter is significantly implicated in the former.

That said, at some variance with latter-day virtue-ethical skill mongers, it is evident that Aristotle distinguishes phronesis no less clearly from techne than from theoria and/or episteme, that the comparison of virtue learning to skill acquisiton of book 2 of the Nicomachean Ethics is only partial and superficial and that he is far from regarding the former as reducible to the latter. In book 6 of the Nicomachean Ethics, for example, he could hardly be clearer that agents are related to their virtues in a radically different way from their skills (Aristotle 1941, book 6, 1140b, 1027). Precisely, he points out that whereas those who possess a skill or technique - such as the ability to play the lyre can make a deliberate mistake in their performance, it is not open to those who genuinely possesses a virtue - such as courage or temperance - to err deliberately (say, by behaving intemperately or in a cowardly way). In Aristotelian terms, the key difference here seems that - notwithstanding that right or good practical conduct is the main point and purpose of virtuous agency - the site or vehicle of such conduct is the character of the agent which is an integral feature of that agent's personhood in a way that his or her skills are not. Becoming courageous, temperate, honest or just is a matter of 'internal' cultivation of attitudes and values more than comparatively detached or disinterested mastery of technique. In this regard, it would seem odd to advise someone who lacks certain virtues to acquire them in quite the manner of a skill. So, for example, if a trainee nurse on a hospital ward seems to be inefficient at making up the beds of patients, we might well say: 'Go over there and practice your bed-making skills'; but if she seems to lack care or compassion, it hardly sounds right to say: 'Go over there and practice your caring skills'. In short, however we might suppose her caring or compassion to be improved, it could hardly be a mere matter of her repetition of caring-like forms of behaviour.

Closer to more present concerns with the epistemic dimensions of practical deliberation, however, there would seem to be significant corresponding differences of substance or content between the premises of techne and phronesis. To consider first a possible fragment of technical deliberation, a (very novice) sculptor might reason: if this is alabastor, then I can chisel it; this is alabastor; therefore I can (or should) chisel it. Bearing in mind that this is an instance of practical deliberation, it is also an item of what Aristotle calls intellectual virtue; but as a whole such inference is not - as Aristotle is equally insistent - a specimen of epistemic or knowledge-seeking virtue. None-the-less, it should be clear that some theoretical and/or factual knowledge is implicated in such inference. On the face of it, notwithstanding that Aristotle seems to have followed the strict Platonic requirement for knowledge to exhibit the certainty of necessary truth, the major premise of this practical inference - that what is of alabastor may be chiselled - would seem to pass more modern epistemic muster as a causal generality supported by past experience. In short, the major premise seems to express a 
principle of general empirical knowledge. However, in order to act with confidence on such a principle, the novice sculptor needs to know that the minor premise is also true: that, precisely, what he or she intends to chisel is a lump of alabastor - not, say, granite or obsidian. This evidently requires perceptual, albeit geologically informed, knowledge of the sensible differences between natural rock types. So while, to repeat, such practical deliberation may not as a whole be considered a type or instance of knowledge, it seems to require knowledge at the levels of major and minor premise.

Turning to the practical deliberation of phronesis, however, matters are evidently less straightforward. As an example of such deliberation, we might consider the following: acting courageously is a means to human flourishing; this is an act of courage; so it is a means to human flourishing. But let us first consider the major premise: can this, as in the previous instance of technical deliberation, be considered a causal principle? The first trouble here is that any claim to the effect that courage is conducive to human flourishing seems to be ambiguous. On one interpretation, only acts of courage or other virtue could conduce to human flourishing, because a life of cowardice or other vice could not be considered a fine or admirable one. But while this does seem consistent with - and is often taken to follow from Aristotelian ethical naturalism - its truth, if true, could hardly be a matter of (contingent) empirical fact. On the contrary, insofar as courage and other virtues are here considered constitutive of a flourishing life, any claim to this effect is clearly normative and therefore true largely by convention or definition: on this reading, it could never be false that the brave do not flourish or that a good man is never harmed. Indeed, this may sound a troubling note for the supposed ethical naturalism of much recent neo-Aristotelian virtue ethics. Still, what if we interpret the connection between virtue and flourishing more empirically: namely, as claiming that acts of courage, self-control or honesty do as a matter of fact bring about human wellbeing or flourishing? The problem now, of course, is that this seems simply false as a descriptive claim about human affairs, since it it is evident that acts of bravery and honesty often lead - on any plausible empirical reading of human flourishing - to the suffering or harm of both individual agents and social collectives. In sum, any attempt to construe the suggestion that virtues are conducive to flourishing as a general truth on the lines of the claim that a certain kind of stone may be chiselled seems caught on the horns of dilemma. On the one hand, it may count as a general truth - but only if it is construed normatively or prescriptively; on the other hand, if it is construed empirically, it seems less generally true. Thus, from the outset, there may be some doubt about the epistemic status of some if not all major premises of the practical deliberations of phronesis.

But what of the minor premises of such deliberations? In the case of technical reasoning, the minor premise is primarily concerned with ascertaining whether or not the objects, circumstances or conditions of present agency are appropriate or conducive to attainment of the goal for which the major premise requires effective means: the sculptor needs to be sure that this lump of rock is alabastor to know whether he or she can chisel it. By the same token, it appears that what the would-be virtuous agent needs to know to be sure that his or her proposed action is an effective means to flourishing is whether this represents an act of courage, temperance or some other virtue. On the face of it, this would also seem a more complex or fraught issue than simply determinng that this lump of rock is alabastor. Indeed, the Nicomachean Ethics offers a special and distinctive account of what it is to determine that this or that proposed action is a virtue 
in the form of the famous - or, perhaps (according to one's view) notorious - doctrine of the mean. On this view, one cannot just see - by simply looking - that this is a courageous or temperate act, as one might perceive by sense experience that this is a lump of alabastor. On the contrary, the whole point of couching virtuous reasoning in terms of practical deliberation is that any satisfactory or adequate appreciation of acts as courageous or temperate requires considered judgement on the basis of mature experience of the nuances and vagaries of human association. To be sure, a key characteristic of such Aristotelian deliberation and judgement is that it is highly contextsensitive, so that what may look like or count as a courageous act in this circumstance may not so appear or count in that one: putting up a fight may be the courageous thing to do in this circumstance (where the matter is serious) whereas it may be just foolish in that one (where the issue is more trivial). In this regard, whether or not recognising alabastor may take experiential knowledge, alabastor is alabastor by virtue of its material nature and one can be plainly right or wrong about this matter. On the other hand, whether or not one should regard this as an occasion for courage, is a matter for judgement - hardly determinable as right or wrong in like fashion - and, indeed, individual agents are liable to irreconcileable disagreement on this and other questions of what here counts as an instance of genune virtuous agency.

This much conceded, it should also be clear that while there may be some disagreement over what is or is not virtuous, there is also much common agreement and clear enough cases in which agents just get things wrong and act conspicuously badly or viciously: Aristotle is no moral subjectivist or relativist and his account of virtuous deliberation clearly aims at right judgement in the best light of knowledge as the grasp of objective truth. Indeed, it is in his discussion of akrasia or incontinence in book 7 of the Nicomachean Ethics that Aristotle seems closest to the view of his philosophical forbear Socrates (also much followed by Plato) that the main source of human vice or moral error is a kind of - perhaps wilful - ignorance whereby agents are distracted from nevertheless available knowledge of what is right and good. On the face of it, while Aristotle is often taken to differ from his distinguished philosophical mentors in taking a more positive view of the role and contribution of emotion, passion and appetite to human affairs, he is nevertheless not far from them in regarding virtue as essentially the rational ordering of such states and conditions to the end of some rational ideal of human flourishing. In this light, while Aristotelian virtue and virtues have a clear affective dimension, this is not a matter of mere brute feeling, but of reason-informed emotion or sentiment. As such, we can be no less mistaken - or liable to correction - with respect to our emotions than with regard to our beliefs or assumptions. This is easily seen in the case of the emotion of jealousy which an agent may well feel justifiably in circumstances of marital infidelity, but not where there is clear evidence that his wife is faithful in thought, heart and deed.

Accordingly, in book 7 of the Nicomachean Ethics) Aristotle compares the incontinent to the drunken who fail to perceive what is correct in their (affectively) intoxicated state. To be sure, John McDowell (1997) has more recently made much of Aristotle's attribution of failures of virtue to misperception - though McDowell inclines to a somewhat problematic agent-privileged account of virtuous perception that renders unclear how any perceptual knowledge of virtue might be communicated to the less than virtuous (at least assuming that knowledge ought to be in principle communicable). More on the heels of Plato, however, Iris Murdoch (see, especially, Murdoch 
1970) also maintains that agents are generally inclined to moral error by way of fairly conspicuous failures of perceptual knowledge: they simply see or read situations wrongly - indeed, in ways that may well be corrected by themselves or with the help of others. On this view, candidate virtuous agents could not be indifferent to the plain truth of matters bearing on virtuous conduct. So, for example, virtuously courageous agents would need to attend to the real hazards of potentially dangerous situations and charitable agents to the real needs of others for which their charity is solicited - and, without such knowledge, courage or charity could only be misplaced or flawed.

To be sure, despite Aristotle's sharp separation of the practical virtues of phronesis from the truth-seeking virtues of episteme, little of this is at odds with what he otherwise maintains in the Nicomachean Ethics about the operations of practical reason as well as appearing generally consistent with the views of Flanagan, Sandler and Winter on the place of and need for knowledge in the practical deliberations of virtue in the case of modesty no less than other virtues. On this view, far from being disposed to the pursuit of ignorance, the virtuously modest should at least aspire to sober and accurate assessment of their own worth and achievements consistent with not overstating these. But what here goes for modesty must also go for most other commonly recognised virtues. In order to be truly brave, self-controlled, generous, charitable, patient, grateful, sympathetic and so on, capacities for epistemically reliable discernment of circumstances relevant to the exercise of such virtues - crucially, for the correction of affectively sourced misperceptions of such circumstances (for example, for appreciating misplaced jealousy) - would seem a sine qua non of virtue. For the most part, then, virtue and virtues would appear to require as much knowledge of the world, ourselves and our relationships with others as humanly possible, in order to be exercised responsibly and wisely. Insofar as this is so, Driver's virtues of ignorance virtues that deliberately go out of their way to court knowledge deficit - can and should only be considered normatively unacceptable and objectionable.

\section{Virtues in the Absence of Knowledge}

But does any or all of this preclude virtue in the absence of knowledge? Despite correctly characterising Flanagan's account of modesty as cognitivist - by which he evidently means a knowledge-based view of virtue - Sandler makes an convincing case for virtues in cases where knowledge is not available. While, in the present view, his own account of modesty as a virtue of this type is not compelling - and Flanagan and Winter arguably give more plausible accounts of this trait - Sandler seems on rather better ground with regard to his virtue of tolerance. Hence, if we find ourselves in circumstances in which we disagree on a particular (perhaps moral, religious or political) matter with another person or persons, but lack the knowledge or evidence that would be needed to settle the issue definitively, a tolerant - rather than unyielding or confrontational - attitude might well seem to be the right or virtuous course to take. Such tolerance has, after all, been the cornerstone virtue of modern political liberalism. So, as distinct from cases in which we deliberately sought out ignorance or could not be bothered to find the knowledge or evidence that might bear on the effective conduct of this or that virtue, we could hardly be blamed for failing to discover what is hard if not impossible to find - such as, perhaps, proof of God's existence - and such epistemic 
deficit would seem to speak more in favour of a virtue of live-and-let-live tolerance than vicious intolerance.

Still, what of cases where knowledge $i s$ available, but we cannot now find it - or where, perhaps more to the present issue, we think that we possess the truth but we are mistaken? In this predicament, we may be inclined by practical deliberation to reason as follows: if a person did not mean to injure another person, then he deserves my compassion and/or forgiveness; this person did not mean to injure another; therefore he deserves my compassion and/or forgiveness. As it happens, however, the subject of one's reflections is a cold-blooded killer who deliberately murdered his wife for the insurance money - although no-one could possibly have had firm evidence for this at the time of deliberation. In this case, since at least one of the premises of this argument is false, it would appear to undermine the supposed case for the virtue of forgiveness though it might not, as we shall see, undermine the case for forgiveness as such. Still, the present concern is with the place of knowledge in practical deliberation and the implications of this for the sort of virtue that the wisdom of phronesis seeks to enable. In this light, the first questions about this example might be about whether a false minor premise invalidates practical deliberation and/or whether this in turn means that there could be no genuine virtue of forgiveness in the light of mistaken reasoning.

With regard to the first of these questions, it should be clear enough that a false premise does not invalidate practical deliberation any more than it would invalidate an instance of theoretical reason: while the reasoning is certainly mistaken, it is no less evidently valid and the agent does not err in this regard. Still, insofar as such inferences contain untruth, false premises in the case of either theoretical or practical inferences are evidently detrimental to their ultimate rational purposes. Indeed, since it is the precise point of theoretical or epistemic reason to deliver truth, a false conclusion following from an untrue minor premise is entirely fatal to the purpose of such inference. On the face of it, however, a false minor premise may likewise seem to undermine practical deliberation by fostering inappropriate virtue, such as - in this case - compassion or forgiveness. On this view, it might therefore seem that just as we should regard an agent who reasons from a false premise to a false (or even accidentally true) conclusion in the sphere of theoretical reason as not truly knowledgeable, we should regard one who reasons from a false practical premise to a false practical conclusion as unvirtuous, if not actually vicious. Precisely, an agent who reasons wrongly to forgiveness on the basis of a mistaken minor premise that a guilty person is excusable, may appear to be in much the same boat as the deluded victims of akrasia or weakness of will, who also appear - in the minor premises of their deliberations about temperance or courage - to mistake what are really acts of intemperance or cowardice for their corresponding virtues.

However, there seem to be more dissimilarities and differences here than otherwise. To begin with, the predicament of the would-be but mistaken forgiver is clearly not at all like that of weak-willed agents. Indeed, recalling what would appear to be the main inspiration for Aristotle's 'drunken' akasiacs in the ideas of Socrates and Plato, it is evident that these philosophers regarded non-virtuous or vicious agency as a matter not merely of ignorance or delusion but of wilful and therefore culpable delusion and ignorance: we could know better than we claim to do, but we all too often refuse to face the painful truth that this would entail. As Iris Murdoch puts the matter in a much quoted phrase - which clearly echoes a passage of Plato's Laws expressing much the 
same point (Plato 1961, book 5, 731d-732a, p. 1318) - humans are victims of a 'fat relentless ego' (Murdoch 1970, 52) which prefers to see things as it would like them to be rather than as they are. Thus, whatever the philosophical peculiarities of this notion, akrasia seems understood in all these classic Greek treatments of the topic as a kind of self-deception for which agents may be justly criticized or blamed. However, we need not suppose that this is at all the case of the mistaken would-be forgivers of recent example, who would not in the least have wanted to be misled as they are and whose hearts may be in entirely the right place. Their problem is rather that the evidence needed to get things right is simply not to hand and that they therefore cannot avoid being mistaken. This would also seem to be an inevitable feature of the human condition and cases in which agents act wrongly by misjudging others through helpless knowledge deficit are familiar enough and also fill the pages of literary fiction.

Be this as it may, it might still be insisted that we simply do not in such circumstances get things right in the way that seems required by Aristotle for the proper cultivation or expression of virtue: the mistake of the minor premise - that this agent requires compassion or forgiveness - leads to the unwarranted exercise of these virtues. Still, we need to be precisely clear what kind of mistake this is in order to understand properly its implications for virtue. For while the mistake is certainly an epistemic failure, it is still not evident that it as such undermines the practical deliberation or purposes of phronesis: after all, to the very best of his or her knowledge and with the very best of intentions the agent deliberates validly to the conclusion that he or she should exercise compassion or forgiveness. Here, a common source of error - to which, for example, Winter's account may perhaps be prone - is to understand the deliberation and inference of practical wisdom as in and of itself a species or instance of knowledge: in that case, if the minor premise is false then the inference as a whole cannot be true or correct - and hence any consequent action could hardly be virtuous. But Aristotle could hardly be clearer in denying that practical deliberation is a form of knowledge - at least in the 'strong' epistemic or propositional sense of Flanagan. Since the concern of such deliberation lies with judging how it is best to act in often uncertain circumstances, it seems - insofar as it may be called a form of knowledge at all - more like the know-how of skill than such strong or propositional knowledge. As such, its key purpose lies less with the discernment of truths, more with the cultivation of excellences of character (virtues) apt for actions conducive to human wellbeing or flourishing.

On this understanding of practical deliberation, it may seem harder to see the adverse implications for virtue or virtuous conduct of deliberations of mistaken minor premise. First, the deliberating agent reasons entirely validly to the conclusion that the subject of deliberation should be shown compassion or be forgiven. Such reasoning is conducted with best of knowledge and intentions, without self-serving or ulterior motives and is entirely to the purpose of due consideration and justice to others and the public good. The agent is mistaken, but his or her mistake is honest and unavoidable error and not at all a matter of self-deception or weakness of will. That said, since the epistemic error does result in an inappropriate display of compassion or forgiveness towards the undeserving, should we not say - since, for Aristotle, virtue requires acting in the right manner, to the right person, at the right time, in the right circumstance and so on - that it cannot count as virtue or virtuous? However, any such judgement seems excessively severe and hardly convincing. In this particular example, valid practical deliberation delivers no less and no more than the cultivation of the genuine virtue in the agent that 
it is designed to do. Indeed, given that compassion and forgiveness are virtues that may be shown even to the underserving, one might not find them - albeit possibly here misplaced - entirely untoward in this circumstance. But lest this example appears too favourable to the present case, other cases may serve no less well. Thus, a courageous person might reason that while courage is generally conducive to flourishing, forbearance rather than confrontation is more in keeping with courage in this situation. This deliberation is based on best present judgement and not upon any fear of confrontation on the part of the agent, but is in the event mistaken - since this was a (bullying) situation precisely warranting confrontation. The courageous agent's reasoning is though not invalid - certainly in error and the resultant conduct inappropriate. But should we also want to say that either reason or action are not here virtuous (compassionate, courageous, temperate or whatever)? Apart from all else, to insist that they are not would seem much at odds with Aristotle's own observation (Aristotle 1941, book 1, chapter 7, 1098a, 943) that 'one swallow does not make a summer': as in the case of overall human flourishing, actions are not to be counted as virtuous or vicious on their own, but need to be considered as such or otherwise by reference to the characters of agents from which they issue or to which they contribute. So considered, despite any particular inappropriateness of their actions on this or that occasion, it seems unreasonable to regard the forgiving and forbearing agents of our examples - or their actions - as other than generally virtuous.

\section{Virtue Ambivalence and Conflict despite Knowledge}

According to the story so far, it seems that while knowledge - of the strong propositional variety - is a strong desideratum of the virtue of practical wisdom - it may not be absolutely necessary. Apart from the fact that, as Sandler maintains, there is a case for virtues such as tolerance that may be required in the absence of knowledge, it seems that agents can be genuinely mistaken about the objects or circumstances of their proposed actions - and hence act inappropriately (though obviously not viciously) and yet still count as generally virtuous. It does not seem reasonable to count one or even a few errors or miscalculations as fatal to the agent's status as virtuous and such lapses are more or less inevitable consequences of human epistemic limits. However, it also seems that full access to virtue-relevant knowledge may not either be sufficient to determine or indicate the precise course or direction that virtuous conduct should take. This is not the usual complaint against Socratic wisdom that one might well have complete knowledge of what is required for virtuous conduct and yet fail - for this or that reason or weakness - to act as required. While this may or may not be so, the present point is rather that even with complete and accurate knowledge and the best will in the world, agents may still not be adequately well placed to decide how they should act in the name of virtue in this or that circumstance.

In fact, we have already given an example in which such indeterminacy is plainly apparent. In the case lately considered, an agent aims to act virtuously under the guidance of practical delberation, but mistakenly (though validly) concludes on the basis of a faulty minor premise that he or she should show compassion or forgiveness to a guilty party. All the same, it may yet be unclear how a virtuous agent should act in the clear light of evidence that the subject of practical deliberation is in fact guilty of a 
hitherto unverified crime. On the one hand, such an agent could argue that since the other party is a cold-blooded killer he or she is undeserving of compassion or forgiveness and that justice demands punishment for such crime. However, given the complex and vexed nature of compassion and forgiveness as virtues without obvious Aristotelian 'means' or limits, it might be held that irrespective of the severer judgements of morality and law, such offenders deserve no less compassion and/or forgiveness than other actually or potentially sinful humans. Again, if this example - drawing as it does on more controversial and contested virtues - should be held to load the case too much in favour of the present argument, it is not hard to make the same point with the help of less controversial virtues.

Thus, for a fairly low-key instance, suppose that a personally introverted agent of overall virtue is both temperate to the point of preferably abstemious, but also courteous and considerate. A more extroverted friend, to whom this agent has done a large favour, is holding a lavish celebration in his honour with the aim of giving him a good time. While the introvert knows that he will be expected to eat, drink and make make merry and knows rightly that his friend will be hurt if not offended if he does not - he also feels uncomfortable on occasions of this sort and disinclined to the excesses towards which he will be encouraged to participate. He is therefore faced with a choice between refusing to accept the invitation or attending the event with his usual reserve and/or without heart-felt involvement - in which case his host may be hurt or offended - or participating with more abandon or indulgence than he would like (with the subsequent embarrassment and hangover) in order to please his friend. While this example may not be of the utmost moral gravity, the situation is no doubt humanly common enough and it is also one that seems easily adaptable to more morally serious cases. In such cases, agents may be faced with unavoidable dilemmas in which they do not know whether it is morally best to be honest at the price of compassion or compassionate at the cost of truth: so, for example, one marital partner - with accurate knowledge of the hurt it will cause - may be torn between whether to tell the truth that the other party is no longer loved or to continue living a lie to save another's pain. To be clear, the issue here is also not - as may be thought - one of conflict or choice between opposing virtues, since a conflicted agent may fully value the virtues of both honesty and compassion and possess them in equal abundance. Rather, it is an uncertainty that generally virtuous agents - in full possession of any knowledge needed for valid and true practical deliberation - may well face about what to do in the inevitably contingent course of human affairs. Whatever knowledge might be required for any or all virtue may yet be insufficient in and of itelf to determine what the best action might here be. There may well be significant moral loss whatever the agent does and little to be gained by taking one course of action rather than another.

In the name of reason, then, what might help to determine a way forward with such dilemmas? In the event, it is far from clear that there is any one right way - though there may seem to be more or less compelling possibilities in this direction. The most immediately attractive of these might seem to some form of consequentialism or utilitarianism framed in terms of the avoidance of harm or pain: thus, in terms of recent examples, it might be said that the right way for the now unloving partner to proceed would be to conceal the truth that would cause the other harm or pain. But while harm and pain may often go together, they are not obviously the same thing and the moral harm that one may do by denying the truth to another party may be greater - as well as 
considered by the other party to be so - than any pain or distress caused by the honest truth. Indeed, insofar as the sort of moral dilemmas and conflicts here at issue are all too often conflicts between general moral principles such as honesty and equal regard on the one hand and considerations of harmful or painful consequence on the other, these may hardly be resolved by appeal to consequences in any way that does not beg the question. In short, it may well be the ultimate implication of Aristotle's contention in the Nicomachean Ethics that practical questions such as these require deliberation precisely because, as distinct from what might be expected in reasonings about matters of plain knowledge and truth, there are no precisely correct or unequivocal solutions in which case we might often have to settle for one or other of a range of less than satisfactory or mutually contradictory options. But, then, one might ask, what could be the point of practical deliberation? Might one not just act on the basis of unreflective sentiment or intuition without unnecessary or futile deliberative agonising?

However, any such pessimistic conclusion may itself follow from some misunderstanding of the nature and purposes of practical deliberation. Clearly, for Aristotle, right or virtuous conduct is distingushed from conduct that is not so by its accountability to phronesis or practical deliberation - which in order to qualify as a genuine form of reason must also, contra Driver, be involved or implicated in knowledge of world, self or others. That said, since right conduct and virtuous conduct are by no means the same thing, it cannot follow that phronesis as practical deliberation is only or even primarily concerned with accurate calculation of the rightness of action on this or that particular occasion. Indeed, it is significant here that while Aristotle certainly does take practical deliberation to be significantly concerned with calculation of appropriate action, he observes little or no formal distinction between the inference of practical wisdom as directed to this end and the mere 'cleverness' of technical reasoning. But, in that case, we might observe no difference between a deviously 'clever' agent who performs a right or good action on behalf of another for purposes of self-interested manipulation and one who acts out of genuine concern for the other. However, there is clearly all the difference in the world. To be sure, what distinguishes the right or good conduct of practical wisdom from that of mere cleverness is that it is conduct arising from the good character of virtue. So while inferential and/or epistemic accuracy remains a significant desideratum of the deliberations of practical wisdom - and notwithstanding that the actual conduct of those of good or virtuous character may not be entirely immune to rational or epistemic error - its role in the formation of virtuous character is no less, if not more, important than such accuracy, not least in those cases where it is prey to error.

In conclusion, it should be clear enough that the most knowledge of world, self and others that we are able to acquire is important for good and virtuous conduct even in those cases of moral dilemma in which it is not in and of itself sufficient to determine precisely and unequivocably what should be done for the best. In the spirit of the Socratic sentiment that introduces this paper, while we may not always be entirely clear what is to be done for the moral best of all concerned or even whether we should do this rather than that in circumstances of dilemma genuine knowledge of self, the world and others is nevertheless of the utmost significance for the good character of virtue. Indeed, as Socrates so powerfully insisted, conduct that is rooted in dishonesty to - or deception of - self or others, is no less harmful to its perpetrators than to their victims and hence to be avoided at the gravest of peril to the soul. 
Open Access This article is licensed under a Creative Commons Attribution 4.0 International License, which permits use, sharing, adaptation, distribution and reproduction in any medium or format, as long as you give appropriate credit to the original author(s) and the source, provide a link to the Creative Commons licence, and indicate if changes were made. The images or other third party material in this article are included in the article's Creative Commons licence, unless indicated otherwise in a credit line to the material. If material is not included in the article's Creative Commons licence and your intended use is not permitted by statutory regulation or exceeds the permitted use, you will need to obtain permission directly from the copyright holder. To view a copy of this licence, visit http://creativecommons.org/licenses/by/4.0/.

\section{References}

Annas, J. (2011). Intelligent Virtue. Oxford: Oxford University Press.

Aristotle. (1941). Nicomachean ethics. In R. McKeon (Ed.), The basic works of Aristotle (Vol. 1941, pp. 935111). New York: Random House.

Carr, D. (2016). Virtue and knowledge. Philosophy, 91(357), 375-390.

Carr, D., Arthur, J., \& Kristjansson (Eds.). (2017). Varieties of virtue ethics. London: Palgrave Macmillan.

Driver, J. (1989). The virtues of ignorance. Journal of Philosophy, 86, 373-384.

Driver, J. (2001). Uneasy virtue. Cambridge: Cambridge University Press.

Flanagan, O. (1990). Virtue and ignorance. Journal of Philosophy, 87, 420-428.

McDowell, J. (1997). Virtue and reason. In R. Crisp \& M. Slote (Eds.), Virtue ethics. Oxford: Oxford University Press.

Murdoch, I. (1970). The sovereignty of the good. London: Routledge and Kegan Paul.

Plato. (1961). Laws. In E. Hamilton \& H. Cairns (Eds.), Plato: The collected dialogues. Princeton University Press: Princeton.

Plato. (1993). Republic. (Robin Waterfield Trans.). Oxford: Oxford World Classics.

Sandler, R. (2005). Ignorance and virtue. Philosophical Papers, 34, 261-272.

Stichter, M. (2018). Virtue as a skill. In N. Snow (Ed.), The Oxford handbook of virtue (pp. 57-81). Oxford: Oxford University Press.

Winter, M. J. (2012). Does moral virtue require knowledge? A response to Julia Driver. Ethical Theory and Moral Practice, 15, 533.

Publisher's Note Springer Nature remains neutral with regard to jurisdictional claims in published maps and institutional affiliations. 